\title{
Prediction of Leisure Exercise Behaviors \\ A Study on University Students of Hong Kong 推测香港大學生休間運動行為的研究
}

Judy K. NG Tom CUDDIHY

School of Human Movement Studies, Queensland University of Technology, AUSTRALIA

\section{吳葉潔雲 湯・嘉特嶢}

人體動力學學院

澳洲昆士蘭科技大學

\author{
Lena FUNG \\ Department of Physical Education, \\ Hong Kong Baptist University, HONG KONG
}

\author{
傌䔎娜 \\ 香港浸會大學體育學系
}

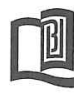

\begin{abstract}
Albstract
The purpose of this study is to examine the theoretical relationships among the variables of leisure exercise efficacy, leisure exercise motives, leisure exercise barriers, and leisure exercise behaviors of university students using the social cognitive theory as a framework. The Model of University Students' Leisure Exercise Behaviors (MUSLEB) was hypothesized before data collection to investigate the theoretical relationships among the variables. Initially, a total of 331 university students were recruited for this study. Data were collected on two occasions using measuring instruments that included the Leisure Exercise Efficacy Scale, the Motivation for Physical Activities Measure-Revised, the Leisure Exercise Barrier Questionnaire, and the Leisure Time Exercise Questionnaire. Participants were classified into Physical Education and Non Physical Education groups to examine their differences in leisure exercise behaviors. As no significant difference was found on the leisure exercise behaviors between the two groups at the end of the semester, all the participants were pooled to test the hypothesized model $(\mathrm{n}=172)$. The hypothesized model was found to be acceptable with $\mathrm{x}^{2} / \mathrm{df}=1.85, \mathrm{CFI}=.98$ and RMSEA $=.07$. However, in an attempt to test a more parsimonious model, all non-significant paths were removed from the model and a re-specified MUSLEB was analyzed again. The re-specified model provided evidences $\left(\mathrm{x}^{2} / \mathrm{df}=1.39, \mathrm{CFI}=.98\right.$ and RMSEA $\left.=.05\right)$ that this was tenable and more parsimonious than the hypothesized model. Path analysis results showed that leisure exercise efficacy was found to be a significant and direct predictor of leisure exercise behaviors 3 months after the commencement of the semester. As hypothesized, positive and significant relationships were found between leisure exercise efficacy and leisure exercise motives. However, contrary to expectation, a positive significant effect between post 3-month leisure exercise efficacy and post 3-month leisure exercise barriers was observed. The investigators suggested the evidence gave support for the theoretical model hypothesizing possible external environmental cause on this phenomenon. Limitations and recommendations for the study are discussed.
\end{abstract}

\section{摘 要}

本文以「社會認知理論」為架構, 研究大學生的“休閒運動信心”, “休閒運動動機”, “休閒運動障礙”, 和 “休閒運動行 為” 的理論關係。作者假設了一個 “大學生休閒運動行為模式” 去測試它們的關係。結果顯示 “休閒運動信心”能吻成功地預測三個 月後的“休閒運動行為”。而 “休閒運動信心” 和 “休閒運動動機” 亦有顯著的正相關。不過三個月後的“休閒運動信心” 和“休 閒運動障礙” 卻出乎意料地有顯著正關係。此結果揭示了外在環境因素具潛在影響這個模式的可能性, 作者還提出了此文的限制和 建議。 


\section{Theoretical Framework}

The determinants of leisure exercise behaviors have often been studied. Among various psychosocial determinants, leisure exercise efficacy was considered to be the strongest predictor of leisure exercise behaviors ( Conn, 1998; Duncan \& Stoolmiller, 1993; Rovniak, Anderson, Winett, \& Stephens, 2002). The Social Cognitive Theory (Bandura, 1977, 1986) is one of the commonly used theories for studying avoidance type of human behavior. One of the core aspects of Social Cognitive Theory is the self-efficacy belief which stemmed from the self-efficacy theory. The theory indicates that efficacy beliefs influence people's courses of action effort and perseverance when they encounter adverse situations (Bandura, 1997). According to this theory, people with a strong sense of selfefficacy pay more effort and persist longer when facing challenging tasks than those with a weaker sense.

Part of understanding leisure exercise behaviors involves discerning the motives behind it. The positive causal relationship between participation motives toward leisure exercise has been well documented (Biddle, 1992; Mathes \& Battista, 1985). The predictive role of exercise motive in leisure exercise was supported by Iso - Ahola \& St. Clair (2000). Exercise motive is a psychological mechanism that directs exercise behaviors. In other words, exercise motive is one of the determinants of leisure exercise behaviors. Bandura (1977) stated that behavior, internal personal factors and the external environment are three major determinants of human behavior and they interact in a triadic reciprocal causation. Human behavior is influenced by the interaction of an individual's internal factors and his/her perceptions about the environment where the behavior is executed. Perceived exercise barriers affect people's decisions concerning their leisure exercise behaviors. People may decline from participating in leisure exercise when they perceive a barrier. The negative relationship between leisure exercise barriers and leisure behaviors was described by Conn (1998) using a path model.

Exercise self efficacy, exercise motives and exercise barriers have been shown to be important determinants in leisure exercise behaviors (Wu, Ronis, Pender, \& Jwo, 2002). The relationship among these variables is one of the themes in contemporary research (Oman \& McAuley, 1993). They suggested that complete theoretical model should be employed to examine the relationships between predictive variables and leisure exercise behaviors.
To assist university students in adopting physically active lifestyles is an integral part of the mission of the university education. The university environment has been suggested to be a positive setting for the promotion of leisure exercise behaviors (Calfas et al., 2000; Rovniak, Anderson, Winette, $\&$ Stephens, 2002). It may be suggested that a common concern of most Leisure Studies and Physical Education university personnel is the enhancement of students' leisure exercise behaviors for their health benefits. These staff are generally interested in whether or not leisure exercise efficacy, leisure exercise motives and leisure exercise barriers are related to students' leisure exercise behaviors. There are eight universities in Hong Kong and only two of them offer a required physical education program for the students. This study concerns students in one of these two universities. They are required to choose two different physical education subjects throughout their 3 -year study in the university. Normally students would enroll in the required physical education program in their first year of study. This study was designed to explore university students' leisure exercise behavior determinants and their inter-relationships so that appropriate physical education subjects may be designed to fit students' needs. The main aim of this study was to examine the relative influence of the three selected psychosocial variables on university students' leisure exercise behaviors immediately after the first semester of the academic year. In addition, the investigators wished to determine if there were differences on these variables between students taking or not taking the required physical education program on their leisure exercise behaviors.

A path analysis approach was considered to be the most suitable analytical tool to help clarify the interrelationships of the proposed variables (Pedhazur, 1982) utilized in this study. Based on the literature and the theoretical framework of the Social Cognitive Theory, the authors hypothesized a Model of University Students' Leisure Exercise Behaviors (MUSLEB) (Figure 1) before data collection to investigate the theoretical relationships among the leisure exercise efficacy (LEE), leisure exercise motives (LEM), leisure exercise barriers (LEB) and leisure exercise behaviors (LEBE) of university students. Self-efficacy has been shown to be the strongest predictor of exercise behaviors, the proposed model was therefore summarized in the following five propositions. First, the time 1(T-1) (at the beginning of the first semester) LEE was posited to have a direct impact on T-1 LEM and LEB. LEBE was not measured at T-1 because the focus of this study was to examine the leisure exercise behaviors of the students three months after the commencement of the new semester-end of the first semester. Second, T-1 LEE was expected to directly 
influence time 2 (T-2) (3 months after the commencement of the semester) LEE, LEM, LEB and LEBE. Third, T-1 LEM and T-1 LEB directly influenced T-2 LEM and T-2 LEB respectively. Fourth, T-2 LEE was proposed to have direct influence on T-2 LEM and T-2 LEB. Finally, T-1 LEE was postulated to mediate the influence of T-2 LEE; T-1 and T2 LEM; and T-1 and T-2 LEB on T-2 LEBE.

Figure 1. A Hypothesized Model of University Students' Leisure Exercise Behaviors (MUSLEB).

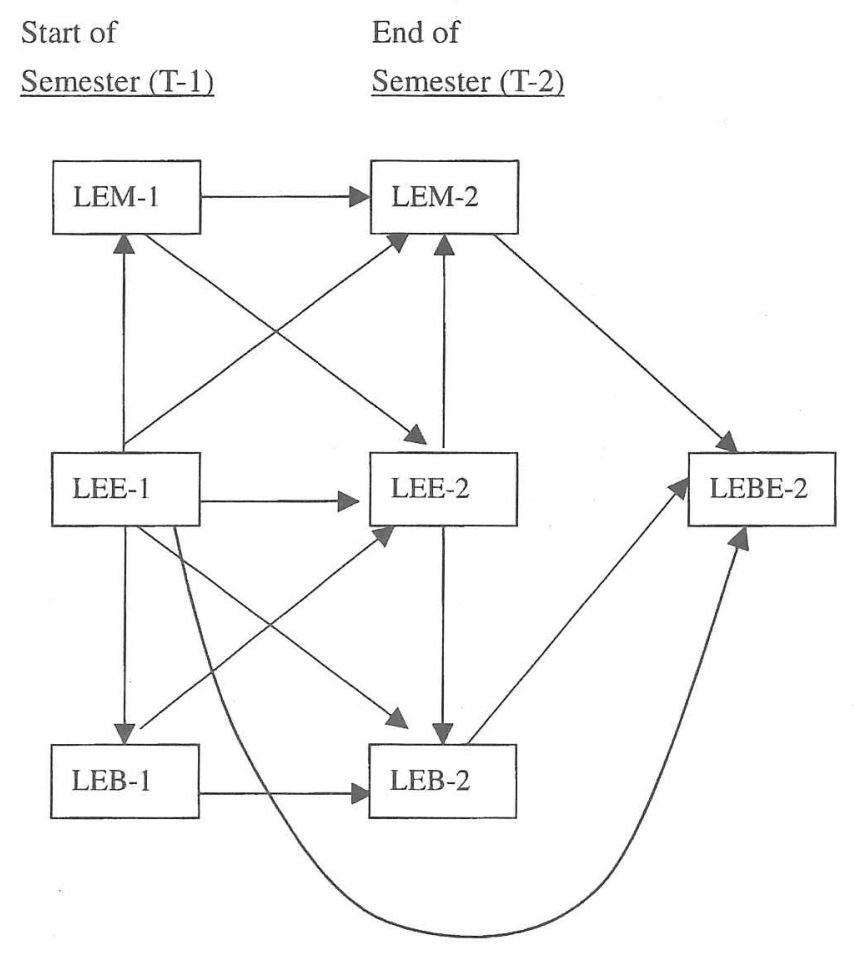

LEE- Leisure Exercise Efficacy

LEM-Leisure Exercise Motives

LEB-Leisure Exercise Barriers

LEBE-Leisure Exercise Behaviors
Method

\section{Participants}

The participants were undergraduate students from one of Hong Kong's universities. Initially, a total of 331 students (male=137, female $=194$ ) volunteered to participate in this study. They were first year to final year undergraduate students, and were classified as Physical Education (PE) and Non Physical Education (NPE) groups. This classification was utilized to provide information on the effect of the university required PE program on the enhancement of leisure exercise behaviors. The PE group consisted of 110 students ( $M=58, F=52)$ enrolled in a Conditioning and Fitness program for the first semester and NPE group consisted of 221 students $(M=79, F=142)$ with no physical education class for that semester. The Conditioning and Fitness program was chosen for this study because all other PE programs offered by the University were considered to be too sport-specific. As the study collected data at two points of time which were separated by 3 months, some participants dropped out from the study. After preliminary data cleaning, only 93 participants (male $=50$, female $=43$ ) (mean age $=19.38, \mathrm{SD}=.98$ ) remained in the $\mathrm{PE}$ group while 147 participants (male $=53$, female $=94)$ (mean age $=19.54, \mathrm{SD}=1$. 77) remained in the NPE group. This constituted $72.5 \%$ of the original sample. Prior to data collection, the investigators had secured informed consents from the participants and approval to conduct the study from the appropriate University committee.

\section{Measurement Instruments}

\section{Leisure Exercise Efficacy Scale (LEES)}

The selection of the leisure exercise efficacy examined in this study was based on reported literature (Courneya \& McAuley, 1994; Duncan \& Stoolmiller, 1993; Dzewaltowski, 1989; Labbe \& Welsh, 1993; McAuley, Lox \& Duncan, 1993; Sallis, Pinski, Grossman, Patterson, \& Nader, 1988). As selfefficacy measures must be situation specific and not generalized, the investigators developed an instrument-the LEES to conceptualize the leisure exercise efficacy of the university students. It assesses the university students' level of confidence to maintain an exercise program during their leisure time for three months under nine adverse situations. Details of the development and validation of the LEES were reported elsewhere (Ng, Cuddihy \& Fung, 2003) (Appendix 1). 
Motivation for h»ysical Activities Measure-Revised (MPAM-R) (Ryan, Frederick, Lepes, Rubio \& Sheldon, 1997)

The MPAM-R (Ryan, Frederick, Lepes, Rubio \& Sheldon, 1997) was used to assess the leisure exercise motives of the participants. This questionnaire was chosen because it was reported to be a valid tool to measure exercise behavior. The participants were requested to respond to the 30 items on a 7-point scale ranging from 1(low) through 7 (high). It was reported that the original five factors accounted for $66 \%$ of the variance and the alphas ranged from .78 to .92 . As the investigators were only interested in the summative value of the MPAM-R in conducting the path analysis of the model, the individual factors were not used in this study.

\section{Leisure Exercise Barriers Questionnaire (LEBQ)}

Based on the questionnaire developed by Raymore, Godbey, Crawford \& Eye (1993) to assess leisure barriers, the LEBQ was developed for this study. As the original questionnaire only focused on perceptions of general leisure barriers when beginning a new leisure activity, the investigators added some items to the original questionnaire and increased the item number from 21 to 31 items. The items were re-phrased to suit the university situation. The content (face) validity was reviewed and approved by a panel of three experts in the physical education and sports psychology fields. According to Nunnally (1978), the reliability of a scale response increased rapidly from a low of 2 scale steps but has the tendency to level off at about 7. Therefore the investigators used the 7-point Likert-type scale response for this questionnaire. The original scale ranged from 1 to 4 . As the content of the LEBQ was different from the original, it was not seen to be important to cross-validate the response similarity of the two questionnaires. Responses were indicated from "Not at all true for me" (1) to "Very true for me" (7). After exploratory factor analysis, the final version of the questionnaire consisted of 19 items with four factors (Social \& Transport, Personalexcuses, Isolation, Personal Insecurity). The factors accounted for $61.24 \%$ of the variance explained. Their factor loadings are presented in Table 1 .

Table 1. The Leisure Exercise Barrier Questionnaire (LEBQ): Factor Loadings Generated from Exploratory Factor Analysis.

\begin{tabular}{llrl}
\hline Item & Loadings & $\begin{array}{l}\text { Percent } \\
\text { Variance }\end{array}$ & Percent Variance \\
\hline
\end{tabular}

Social \& Transport Subscale

Because my friends don't have enough money to do the exercise with me. $\quad .63$

Because I don't have transportation. $\quad .75$

Because my friends have too many obligations to do the exercise with me. .63

Because the exercise is not in keeping with my religious beliefs. $\quad .76$

Because my friends don't have enough skills to do the exercise with me. 68

Because my friends don't have transportation to get to exercise with me. $\quad .71$

Because my friends don't know what new leisure activities would interest me $\quad .56$

Personal-excuses Subscale

Because the exercise makes me feel uncomfortable. $\quad .59$

Because exercise is boring $\quad .81$

Because I'm afraid of injury. $\quad .68$

Because exercise is painful. $\quad .74$

Because I feel tired or lack of energy.

Because I'm too lazy. $\quad .62$

Because I am not interested $\quad .80$

Isolation Subscale

Because my friends live too far away to do the exercise with me. $\quad .80$

Because the facilities I need to do the activity are too crowded.

Because my friends don't have time to do the exercise with me. $\quad .78$

Personal Insecurity Subscale

Because I'm too shy.

$34.10 \quad 34.10$

Because I have no self-confidence.

$14.00 \quad 48.10$

68

7.31

55.41

.87

.68 
The participants were asked to rate the barriers to their participation in leisure exercise. For the present study, only the sum of the LEBQ responses was used for data analysis. The possible maximum score of the LEBQ is 133 and a high score represents greater perceived barriers to leisure exercise. (Appendix 2).

\section{Leisure Time Exercise Questionnaire (LTEQ) (Godin \& Shephard, 1985)}

The LTEQ (Godin \& Shephard, 1985) was considered to be a valid tool to examine the participants' leisure time exercise behaviors. The reliability and validity of the questionnaire were reported in many studies (Jacobs Ainsworth, Hartman, \& Leon, 1993; Miller, Freedson, \& Kline, 1994; Sallis, Buono, Roby, Micale, \& Nelson 1993) and found to be good. The total test-retest reliability was reported to be .74; and significant correlations with maximum oxygen consumption and body fat were found (.24 and .13 respectively) in a previous study conducted by Godin \& Shephard (1985). It contains two simple questions. This study only used the responses from the first question. The participants were asked to indicate the number of times (sessions longer than 15 minutes) per week they exercised during their leisure time. Their weekly energy expenditure in leisure pursuits was determined by the formula provided by Godin \& Shephard (1985): (9 METS x number of strenuous exercise sessions $)+(5$ METS $x$ number of moderate exercise sessions $)+(3$ METS $x$ number of light exercise sessions).

\section{Procedures}

A two-wave, time-lagged design with two groups (PE \& NPE) was used to test the hypothesized model. Data were collected on two occasions. At T-1 (baseline), participants were asked to respond to the LEES (LEES-1), MPAM-R (MPAMR-1) and LEBQ (LEBQ-1) and LTEQ (LTEQ-1). During the semester, the PE group attended the conditioning and fitness program for three months while the NPE group did not have any PE classes. At T-2 (3 months after time 1 -end of first semester), data collected included responses to the LEES, MPAMR, LEBQ and LTEQ. To distinguish the data generated by these questionnaires at T-1, they were referred to as LEES2, MPAM-R-2, LEBQ-2 and LTEQ-2.

\section{Data Analysis}

All data were input into the computer and analyzed by two statistical software packages. The SPSS 11.0 for Windows was used for preliminary data analysis. The EQS 5.7 for Windows was employed for the evaluation of the hypothesized models and estimation of path coefficient values to quantify the effect of the leisure exercise efficacy, leisure exercise motives and leisure exercise barriers on the leisure exercise behaviors. The Maximum Likelihood (ML) method was used to compute a number of the goodness-of-fit measures to determine if the hypothesized model fit the data. The chi-square test statistics $\left(\mathrm{x}^{2}\right)$ was used to assess the absolute fit between the hypothesized model and the data. Other fit indices used to help evaluate the model fit included comparative fit index (CFI) and root mean square error of approximation (RMSEA). A level of significance of $p<.05$ was used for all path analyses.

\section{Results}

\section{Preliminary Analysis}

As the sample number in the $P E(n=93$, male $=50 \&$ female=43) and NPE $(n=147$, male $=53 \&$ female= 94) groups differed, a factor which might create a computation problem and ambiguous results for the one-way between subjects ANOVA (Tabachnick \& Fidell, 2001), cases were randomly deleted from the sample until the number of PE, NPE, male and female participants were equal. The total number of participants for data analysis was 172 with 43 each in PE, NPE, female and male categories.

\section{Validity of the LEES}

The validity of the LEES-1 in measuring the post 3month leisure exercise behavior was considered to be important in testing the hypothesized model. From the LTEQ-2 score, the participants were classified into three groups according to their weekly leisure MET levels. The upper one third were classified as High Level (35 METs - 105 METs), the middle one third were classified as Medium Level (18 METs - 34 METs) and the lower one third was classified as Low Level (0 - 17 METs). Oneway ANOVA was performed to compare the means between the three leisure exercise levels and the LEES-1. Tukey post-hoc means comparisons of scores on LEES1 for participants in the three LTEQ-2 levels showed that there were significant differences between High Level and Low Level participants, and between Medium Level and Low Level participants. However, no significant difference was found between High Level and Medium Level participants. The results thus provided some evidence for the sensitivity of the LEES-1. 


\section{Internal Consistency of the Measurement Instruments}

Prior to evaluating the MUSLEB, the cronbach's alpha coefficients of each measurement instrument were computed to assure the scales were reliable for the sample of this study. Results revealed that the reliability coefficients for the LEES1, MPAM-R-1 and LEBQ-1 were $.92, .93$ and .88 respectively. All scales were considered to be reliable with all coefficients exceeding .70 (Nunnally, 1978).
Oneway ANOVA was performed to compare the means of all the variables for the PE and NPE groups. The ANOVA results showed that there were no statistical differences between the two groups on baseline LEES $(p=.45)$, MPAM-R $(p=$ $.25), \operatorname{LEBQ}(p=.38)$ and LTEQ $(p=.45)$ scales.

\section{Comparison between the PE and NPE groups}

Means and standard deviations for the LEES, MPAMR, LEBQ and LTEQ are presented in Table 2.

Table 2. Means and standard deviations for the $L E E S, M P A M-R, L E B Q$ and LTEQ (n=172).

\begin{tabular}{lllll}
\hline & \multicolumn{2}{c}{ PE } & \multicolumn{2}{c}{ NPE } \\
& $\begin{array}{l}\text { Baseline } \\
\text { Mean (SD) }\end{array}$ & $\begin{array}{l}\text { 3-months after } \\
\text { Mean (SD) }\end{array}$ & $\begin{array}{l}\text { Baseline } \\
\text { Mean (SD) }\end{array}$ & $\begin{array}{l}\text { 3-months after } \\
\text { Mean (SD) }\end{array}$ \\
\hline LEES & $433.84(158.92)$ & $435.12(141.39)$ & $414.42(174.81)$ & $434.42(150.89)$ \\
MPAM-R & $138.07(28.01)$ & $141.06(24.64)$ & $133.22(26.56)$ & $132.79(24.79)$ \\
LEBQ & $53.40(15.67)$ & $58.08(15.57)$ & $55.64(17.83)$ & $64.44(18.89)$ \\
LTEQ & $30.79(26.86)$ & $27.70(27.09)$ & $28.65(15.36)$ & $26.41(22.54)$ \\
\hline
\end{tabular}

The Pearson correlations of the variables in the proposed model are presented in Table 3. Results of the correlational analysis showed that only nine out of the twenty-one correlations supported the predicted relationships. The LTEQ-2 was only positively correlated with the LEES1 and LEES-2.

Table 3. Pearson Correlations of the Seven Variables in the Proposed Model ( $n=172)$.

\begin{tabular}{|c|c|c|c|c|c|c|c|c|}
\hline & & 1 & 2 & 3 & 4 & 5 & 6 & 7 \\
\hline 1. & LEES-1 & 1.00 & & & & & & \\
\hline 2. & LEES-2 & $.51^{*}$ & 1.00 & & & & & \\
\hline 3. & MPAM-R-1 & $.47^{*}$ & $.24^{*}$ & 1.00 & & & & \\
\hline 4. & MPAM-R-2 & $.44 *$ & $.56^{*}$ & $.46^{*}$ & 1.00 & & & \\
\hline 5. & LEBQ-1 & -.07 & -.05 & .03 & -.07 & 1.00 & & \\
\hline 6. & LEBQ-2 & -.08 & .14 & -.04 & .02 & $.41^{*}$ & 1.00 & \\
\hline 7. & LTEQ-2 & $2.7^{*}$ & $.34 *$ & .21 & .23 & -.08 & -.08 & 1.00 \\
\hline
\end{tabular}

*Significant after Bonferroni adjustment $(\mathrm{p}<.002)$

adjusted $p$ level $=.05 / 21=.002$ 
The Oneway ANOVA results indicated that there were no statistical differences between the PE and NPE groups 3 months after the commencement of the semester on leisure exercise behaviors $(p=.45)$. This result indicated that students whether they were enrolled or not in a required physical education program did not differ in their leisure exercise behaviors. In this case, it was meaningless to test two separate models for the PE and NPE groups. The investigators decided to pool the PE and NPE data to test the hypothesized model.

\section{Path Analysis of the Model}

The hypothesized path diagram with path coefficients and squared multiple correlations is shown in Figure 2.

Figure 2. A Hypothesized Model of University Students" Leisure Exercise Behaviors (MUSLEB) with Path Coefficients.

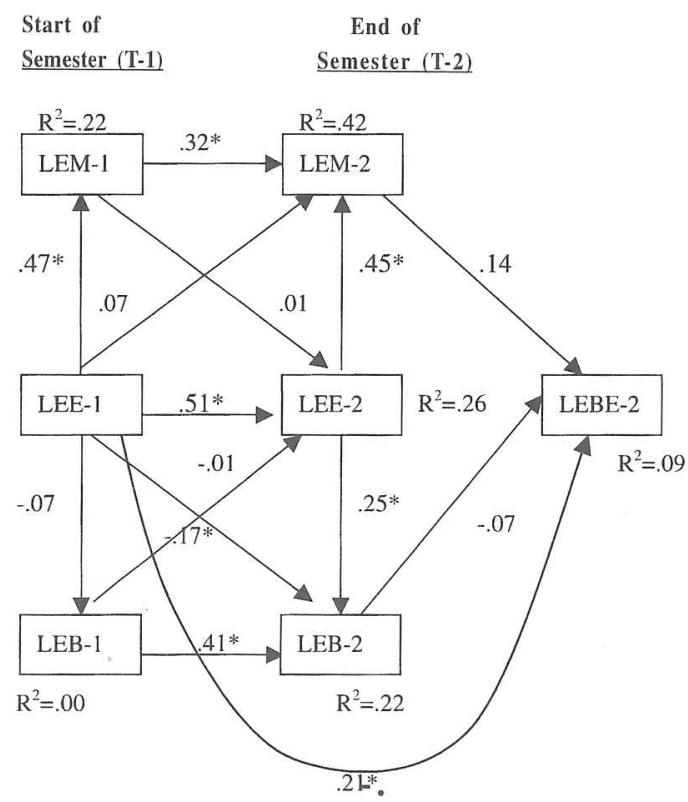

LEE_ Leisure Exercise Efficacy
LEM-Leisure Exercise Motives
LEB-Leisure Exercise Barriers
LEBE-Leisure Exercise Behaviors

$* p<.05$

Eight of the hypothesized paths were significant. The T-1 LEE (.47, $t=6.89, p<.05)$ significantly influenced T1 LEM and accounted for $22 \%$ of the variance. The T-1 $\operatorname{LEM}(.32, t=4.79, p<.05)$ and T-2 LEE $(.45, t=6.56$, $p<.05)$ significantly predicted T-2 LEM and accounted for $42 \%$ of the variance. The T-1 LEE $(-.17, t=-2.18$, $p<.05), \mathrm{T}-1 \mathrm{LEB}(.41, t=5.96, p<.05)$ and T-2 LEE $(.25, t=3.07, p<.05)$ significantly predicted T-2 LEB and accounted for $22 \%$ of the variance. The T-1 LEE was a significant predictor of T-2 LEE $(.51, t=6.81, p<.05)$ and accounted for $26 \%$ of the variance. The T-1 LEE was a significant predictor of the T-2 LEBE $(.21, t=2.54, p<.05)$ and accounted for $9 \%$ of the variance.

The model fit the data with a chi-square of $12.94(d f=7$, $p=.07)$. The Likelihood-Ratio chi-square statistics $(\sim 2 / \mathrm{df})$ was 1.85 and considered to be acceptable (Joreskog, 1969). The comparative fit index was .98 and the RMSEA was. 07.

In an attempt to test a more parsimonious model, nonsignificant paths were removed from the model and the respecified model was analyzed again. The re-specified model with path coefficients and squared multiple correlations is presented in Figure 3.

Figure 3. A Respecified Model of University Students' Leisure Exercise Behaviors (MUSLEB)
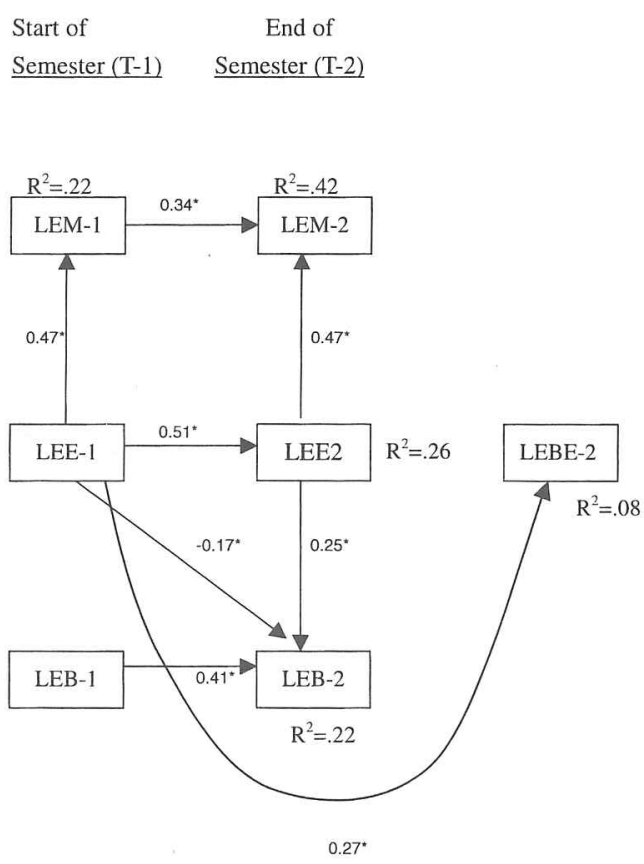

LEE - Leisure Exercise Efficacy

LEM-Leisure Exercise Motives

LEB-Leisure Exercise Barriers

LEBE-Leisure Exercise Behaviors

$* p<.05$ 
Similar results were obtained for the path coefficients of the re-specified model. The T-1 LEE $(.47, t=6.87$, $p<.05)$ significantly influenced T-1 LEM and accounted for $22 \%$ of the variance. The T-1 LEM $(.34, t=5.62, p<.05)$ and T-2 LEE $(.47, t=7.83, p<.05)$ significantly predicted T-2 LEM and accounted for $42 \%$ of the variance. The T-1 LEE $(-.17, t=-2.18, p<.05)$, T-1 LEB $(.41, t=5.95$, $p<.05)$ and T-2 LEE $(.25, t=3.06, p<.05)$ significantly predicted T-2 LEB and accounted for $22 \%$ of the variance. The T-1 LEE was a significant predictor of T-2 LEE (.51, $t=7.75, p<.05$ ) and accounted for $26 \%$ of the variance. The T-1 LEE was a significant predictor of the T-2 LEBE $(.27, t=3.70, p<.05)$ and accounted for $8 \%$ of the variance.

The re-specified model fit the data with a chi-square of $18.09(d f=13, p=15)$. The Likelihood-Ratio chi-square statistics $\left(\mathrm{x}^{2} / \mathrm{df}\right)$ was 1.39 and considered to be acceptable (Joreskog, 1969). The comparative fit index was .98 and the RMSEA was .05 . The CFI obtained from the two models were all .98. According to Schumacker and Lomax (1996), values close to .90 reflect a good model fit, both the results thus represented good-fitting models. For the chi-square and the RMSEA results, the re-specified model was found to have a better fit of the data to the model. Bollen (1989) suggested that the larger the probability associated with the $\mathrm{x}^{2}$, the better the fit of the model to the data. Using the rule of thumb that when the RMSEA of $<.10$ is good and $<.05$ is very good (Loehlin, 1998), the RMSEA of the re-specified model was better than the hypothesized model. All values of the re-specified model provided evidences that this model was tenable and more parsimonious than the hypothesized model.

\section{Discussion}

The use of longitudinal designs and the path analysis method in this study was seen to be suitable to examine the theoretical relationships of the leisure exercise efficacy, leisure exercise motives, leisure exercise barriers and leisure exercise behaviors for the university students.

The findings of the present study are consistent with numerous other studies (Conn, 1998; Duncan \& Stoolmiller, 1993; Rovniak, Anderson, Winett \& Stephens, 2002, Wallace, Buckworth, Kirby \& Sherman, 2000) on the determinants of exercise behaviors. Leisure exercise efficacy was found to have a significant and direct effect on the leisure exercise behaviors after the 3-month semester for the undergraduate students. In terms of the predictive role of the leisure exercise efficacy on leisure exercise motives, significant and positive effects were found for data collected at the same point in time. However, no significant effect was found between baseline leisure exercise efficacy and post 3-month leisure exercise motives. An expected significant negative effect was found between baseline leisure exercise efficacy and post 3-month leisure exercise barriers.

Surprisingly, a positive significant effect was found between the post 3-month leisure exercise efficacy and the post 3-month leisure exercise barriers. From the significant correlation between the LEES-1 and the LTEQ-2 $(r=2.7, p<.05)$, we can confirm that those participants with low leisure exercise efficacy were normally low leisure exercisers and those with high leisure exercise efficacy were normally active leisure exercisers. Therefore the unusual phenomenon may be explained due to the fact that at Time 2 data collection with the approach of the end of semester examinations, the active students reflected their worries in focusing on their perceived leisure exercise barriers. For those low leisure exercisers, as they only spent a little time on leisure exercise and might not perceive the existence of the leisure exercise barriers even when it was near to the final examination. The result was consistent with Bandura's (1997) suggestion that the external environment plays an important role in determining human behavior.

While the MUSLEB may provide useful tool to examine the predictors of leisure exercise behaviors for university students, the following limitations are worth noting. The first limitation was the nature of the participants. This study employed undergraduate students as participants and this greatly limited the generalization of the findings of this study. The second limitation was the lack of significant difference between the PE and NPE groups at the end of the semester and the decision to pool the two groups to test the hypothesized model. The third limitation was the $27.5 \%$ loss of participants due to dropout, data cleaning and the unequal numbers of PE, NPE, male and female participants. After random deletion, only 172 participants were left for data analysis which constituted only $52 \%$ of the original sample. Statistically, the sample size $(\mathrm{n}=172)$ was acceptable for a path model with only four variables (Cohen, 1988), an extension of this finding with a larger sample size to assess on the individual factors of the selected variables is necessary. The fourth limitation was the relatively small variance explained found in this study. The variables in the re-specified model explained less than 10\% of the variance in leisure exercise behaviors $\left(\mathrm{R}^{2}=8 \%\right)$. A majority of the variance remains unexplained. Based on the amount of variance explained, the model was considered to be less 
effective in developing an understanding of the university students' leisure exercise behaviors. The results suggest that other variables may be required to add to the model so as to strengthen the explanatory power of the model. This represents a future direction for research studies to examine the path models of university students' leisure exercise behaviors.

Duncan \& Stoolmiller (1993) stated that the testing of the hypothesized model could enable the researchers to investigate the relationships among the theoretical constructs so as to clarify the hypotheses. Despite the limitations mentioned above, this study could be viewed as a clarification of the possible theoretical relationships between the leisure exercise efficacy, leisure exercise motives, leisure exercise barriers and leisure exercise behaviors for Hong Kong's university students before and after the commencement of the semester.

\section{Authors' Note:}

This paper was completed as part of the requirements for Judy K. Ng's Doctor of Philosophy degree at the School of Human Movement Studies, Queensland University of Technology, Australia.

\section{Appendix 1. Leisure Exercise Self-efficacy Scale (LEES).}

The following 9 situations are sometimes encountered by people when trying to maintain an exercise program. (Exercise is defined as a structured and planned physical activity that has the goal of maintaining or improving physical or psychological fitness).

Please circle the level of confidence that you have in maintaining an exercise program of more than 15 minutes each week during your free time for three months.
Your response is most important and should reflect how confident YOU are (from a range of 0 to 100) in facing different situations, so please respond to the best of your knowledge how you would feel.

Score 0 indicates that you are certain that you cannot adhere to exercise and score $\mathbf{1 0 0}$ indicates that you are certain that you can adhere to exercise.

\begin{tabular}{|c|l|ccccccccccc|}
\hline & \multicolumn{1}{|c|}{ Level of Confidence } \\
\hline 1 & $\begin{array}{l}\text { Adhere to your exercise program in } \\
\text { spite of your work schedule }\end{array}$ & 0 & 10 & 20 & 30 & 40 & 50 & 60 & 70 & 80 & 90 & 100 \\
\hline 2 & $\begin{array}{l}\text { Adhere to your exercise program after a } \\
\text { long tiring day at the University }\end{array}$ & 0 & 10 & 20 & 30 & 40 & 50 & 60 & 70 & 80 & 90 & 100 \\
\hline 3 & $\begin{array}{l}\text { Adhere to your exercise program even } \\
\text { when you have excessive work demands } \\
\text { from the University }\end{array}$ & 0 & 10 & 20 & 30 & 40 & 50 & 60 & 70 & 80 & 90 & 100 \\
\hline 4 & $\begin{array}{l}\text { Adhere to your exercise program even } \\
\text { when you are physically fatigued }\end{array}$ & 0 & 10 & 20 & 30 & 40 & 50 & 60 & 70 & 80 & 90 & 100 \\
\hline 5 & $\begin{array}{l}\text { Adhere to your exercise program in } \\
\text { spite of family responsibilities }\end{array}$ & 0 & 10 & 20 & 30 & 40 & 50 & 60 & 70 & 80 & 90 & 100 \\
\hline 6 & $\begin{array}{l}\text { Adhere to your exercise program even } \\
\text { when social obligations are very time } \\
\text { consuming }\end{array}$ & 0 & 10 & 20 & 30 & 40 & 50 & 60 & 70 & 80 & 90 & 100 \\
\hline 7 & $\begin{array}{l}\text { Adhere to your exercise program even } \\
\text { though when you are feeling depressed }\end{array}$ & 0 & 10 & 20 & 30 & 40 & 50 & 60 & 70 & 80 & 90 & 100 \\
\hline 8 & $\begin{array}{l}\text { Adhere to your exercise program even } \\
\text { when bearing minor injuries }\end{array}$ & 0 & 10 & 20 & 30 & 40 & 50 & 60 & 70 & 80 & 90 & 100 \\
\hline 9 & $\begin{array}{l}\text { Adhere to your exercise program even } \\
\text { when exercise is boring }\end{array}$ & 0 & 10 & 20 & 30 & 40 & 50 & 60 & 70 & 80 & 90 & 100 \\
\hline
\end{tabular}




\section{Appendix 2. Leisure Exercise Barrier Questionnaire (LEBQ).}

The following scale provides a list of potential barriers to participation in exercise activity (Exercise is defined as a structured and planned physical activity that has the goal of maintaining or improving physical or psychological fitness).

Please respond to each question on the basis of how true each response is for you.
You are requested to circle the number on the scale to indicate your response. Score $\mathbb{1}$ indicates that the potential barrier is not at all true for you and score 7 indicates that it is very true for you.

I do not engage in exercise activity.

\begin{tabular}{|c|c|c|c|c|c|c|}
\hline No. & $\begin{array}{l}\text { Not at } \\
\text { all true } \\
\text { for me }\end{array}$ & & & & & $\begin{array}{l}\text { Very } \\
\text { true } \\
\text { for me }\end{array}$ \\
\hline 1 Because I'm too shy. & 1 & 23 & 4 & 5 & 6 & 7 \\
\hline $\begin{array}{l}2 \text { Because my friends live too far away to do } \\
\text { the exercise with me. }\end{array}$ & 1 & 3 & 4 & 5 & 6 & 7 \\
\hline $\begin{array}{l}3 \text { Because the facilities I need to do the } \\
\text { activity are too crowded. }\end{array}$ & 1 & 3 & 4 & 5 & 6 & 7 \\
\hline $\begin{array}{l}4 \text { Because my friends don't have time to do } \\
\text { the exercise with me. }\end{array}$ & 1 & 3 & 4 & 5 & 6 & 7 \\
\hline $\begin{array}{l}5 \text { Because the exercise makes me feel } \\
\text { uncomfortable. }\end{array}$ & 1 & 3 & 4 & 5 & 6 & 7 \\
\hline $\begin{array}{l}6 \text { Because my friends don't have enough } \\
\text { money to do the exercise with me. }\end{array}$ & 1 & 3 & 4 & 5 & 6 & 7 \\
\hline 7 Because I don't have transportation. & 1 & 3 & 4 & 5 & 6 & 7 \\
\hline $\begin{array}{l}8 \text { Because my friends have too many } \\
\text { obligations to do the exercise with me. }\end{array}$ & 1 & 3 & 4 & 5 & 6 & 7 \\
\hline $\begin{array}{l}9 \text { Because the exercise is not in keeping } \\
\text { with my religious beliefs. }\end{array}$ & 1 & 3 & 4 & 5 & 6 & 7 \\
\hline $\begin{array}{l}10 \text { Because my friends don't have enough } \\
\text { skills to do the exercise with me. }\end{array}$ & 1 & 3 & 4 & 5 & 6 & 7 \\
\hline $\begin{array}{l}11 \text { Because my friends don't have } \\
\text { transportation to get to exercise with me. }\end{array}$ & 1 & 3 & 4 & 5 & 6 & 7 \\
\hline 12 Because exercise is boring. & 1 & 3 & 4 & 5 & 6 & 7 \\
\hline 13 Because I'm afraid of injury. & 1 & 3 & 4 & 5 & 6 & 7 \\
\hline 14 Because exercise is painful. & 1 & 3 & 4 & 5 & 6 & 7 \\
\hline 15 Because I feel tired or lack of energy. & 1 & 3 & 4 & 5 & 6 & 7 \\
\hline 16 Because I'm too lazy. & 1 & 3 & 4 & 5 & 6 & 7 \\
\hline $\begin{array}{l}17 \text { Because my friends don't know what new } \\
\text { leisure activities would interest me }\end{array}$ & 1 & 3 & 4 & 5 & 6 & 7 \\
\hline 18 Because I am not interested & 1 & 2 & 4 & 5 & 6 & 7 \\
\hline 19 Because I have no self-confidence. & 1 & 2 & 4 & 5 & 6 & 7 \\
\hline
\end{tabular}




\section{References}

Bandura, A. (1977). Self-efficacy: Toward a unifying theory of behavioural change. Psychological Review, 84, 191215.

Bandura, A. (1986). Social foundation of thought and action: A social cognitive theory. Englewood Cliffs, NJ:PrenticeHall.

Bandura, A. (1997). Self-efficacy: The exercise of control. New York: W.H. Freeman \& Co.

Biddle, S. (1992). Sport and exercise motivation: a brief review of antecedent factors and psychological outcomes of participation. Physical Education Review, 15(2), 98-110.

Bollen, K. (1989). Structural equations with latent variables. New York: John Wiley \& Sons.

Calfas K.J., Sallis J.F., Nichols J.F., Sarkin J.A., Johnson M.F., Caparosa S., Thompson S., Gehrman C.A., \& Alcaraz J.E. (2000). Project GRAD: Two-year outcomes of a randomized controlled physical activity intervention among young adults. American Journal of Preventive Medicine, 18(1), 28-37.

Cohen, J. (1988). Statistical power analysis for the behavioral sciences $\left(2^{\text {nd }}\right.$ ed.). Hillsdale, New Jersey: LEA.

Conn, V.C. (1998). Older adults and exercise. Path analysis of self-efficacy related constructs. Nursing Research, 47 (3), 180-189.

Courneya K.S., \& McAuley E.(1994). Are there different determinants of the frequency, intensity, and duration of physical activity. Behavioral Medicine, 20, 84-90.

Duncan T.E., \& Stoolmiller M. (1993). Modeling social and psychological determinants of exercise behaviors via structural equation systems. Research Quarterly for Exercise \& Sport, 64, 1-16.

Dzewaltowski, D.A. (1989). Toward a model of exercise motivation. Journal of Sport and Exercise Psychology, 11, 251-269.
Godin G., \& Shephard R.J. (1985). A simple method to assess exercise behavior in the community. Canadian Journal of Applied Sport Science, 10(3), 141-146.

Iso-Ahola, S.E., \& St. Clair, B.(2000). Toward a theory of exercise motivation. QUEST, 52, 131-147.

Jacobs, D.R. Jr., Ainsworth, B.E., Hartman, T.J., \& Leon, A.S. (1993). A simultaneous evaluation of 10 commonly used physical activity questionnaires. Medicine and Science in Sports and Exercise, 25, 81-91.

Joreskog, K.G. (1969). A general approach to confirmatory maximum likelihood factor analysis. Psychometrika, 34, 183-202.

Labbe E.E., \& Welsh C. (1993). Children and running: Changes in physical fitness, self-efficacy, and health locus of control. Journal of Sport Behavior, 16, 85-97.

Loehlin, J. (1998). Latent variable models. Mahwah, NJ: Lawrence Erlbaum.

Mathes, S.A., \& Battista, R. (1985). College men's and women's motives for participation in physical activity. Perceptual and motor skills, 61, 719-726.

McAuley E., Lox C., \& Duncan T.E. (1993). Long-term maintenance of exercise, self-efficacy, and physiological change in older adults. Journal of Gerontology, 48, 218 224.

Miller D.J., Freedson, P.S., \& Kline, G.M. (1994). Comparison of activity levels using caltrac accelerometer and five questionnaires. Medicine and Science in Sports and Exercise, 26, 376-382.

Ng, J.K., Cuddihy, T., \& Fung, L. (2003). The development and validation of a leisure exercise efficacy scale for university students: A Hong Kong study. ACHPER Healthy Lifestyles Journal, 50(1), 18-23.

Nunnally, J.C. (1978). Psychometric Theory, (2 ${ }^{\text {nd }}$ ed.). New York: McGraw-Hill Book Company.

Oman, R., \& McAuley, E. (1993). Intrinsic motivation and exercise behavior. Journal of Health Education 24(4), 232-238. 
Pedhazur, E. (1982). Multiple regression in behavioral research ( $2^{\text {nd }}$ ed.). Chicago, IL: Holt, Rinehart and Winston.

Raymore, L., Godbey, G., Crawford, D., \& Eye, A. (1993). Nature and process of leisure constraints: an empirical test. Leisure Science, 15, 99-113.

Rovniak, L.S., Anderson, E.S., Winett, R.A., \& Stephens, R. S. (2002). Social cognitive determinants of physical activity in young adults: A prospective structural equation analysis. Annals of Behavioral Medicine, 24(2), 149-156.

Ryan R., Frederick C.M., Lepes D., Rubio N., \& Sheldon, K.M.(1997). Intrinsic motivation and exercise Adherence. International Journal of Sport Psychology, 28, 335-354.

Sallis, J.F., Pinski, R.B., Grossman, R.M., Patterson, T.L., \& Nader, P.R. (1988). The development of self-efficacy scales for health-related diet and exercise behaviours. Health Education Research-Theory \& Practice, 3(3), 283-292.

Sallis, J.F., Buono, M.J., Roby, J.J., Micale, F.G., \& Nelson, J.A. (1993). Seven-day recall and other physical activity self-reports in children and adolescents. Medicine and Science in Sports and Exercise, 25, 99-108.

Schumacker, R.E., \& Lomax, R.G. (1996). A beginner's guide to structural equation modeling. Mahwah, N.J. : L. Erlbaum Associates.
Tabachnick, B.G., \& Fidell, L.S. (2001). Using multivariate statistics (4thed.). Boston: Allyn and Bacon.

Wallace, L.S., Buckworth, J., Kirby, T.E., \& Sherman, W. M. (2000). Characteristics of exercise behavior among college students: application of social cognitive theory to predicting stage of change. Preventive Medicine, 31, 494-505.

Wu, T.Y., Ronis, D.L., Pender, N., \& Jwo, J.L. (2002). Development of questionnaires to measure physical activity cognitions among Taiwanese adolescents. Preventive Medicine, 35, 54-64.

\section{Correspondence:}

Judy K. Ng

c/o Department of Physical Education

Hong Kong Baptist University

Kowloon Tong

Hong Kong

Email:judyng@hkbu.edu.hk 